\title{
Experimental Investigation and Reaction Kinetics Modeling of Biomass Formation, Substrate Consumption and Product Formation During Start- up of Fixed-Bed Cultures with Immobilized Lactococcus lactis ssp. lactis
}

Rebecca Faschian, Steven Minden and Ralf Portner*

Institute of Bioprocess and Biosystems Engineering, Hamburg University of Technology, Hamburg, Germany

\begin{abstract}
Lactic acid bacteria (LAB) like Lactococcus lactis ssp. lactis are used in food industry as well as for production of bacteriocins and optically pure lactic acid. Fixed-bed processes are highly productive but mathematical description is often complex. The aim of this work was to establish a mathematica model for process design. Biomass formation, lactose consumption and lactate production during start-up of fixed-bed cultures with immobilized L. lactis was investigated experimentally and described by a reaction kinetics model. Appropriate modeling and simulation of fixed-bed processes require biomass data. Therefore, a low-volume multiple fixed-bed reactor system (Multiferm) was used to investigate biomass formation of a $L$. lactis strain during the start-up phase of fixed-bed cultivation. The generation of data in parallel experiments was fast and easily compared to larger single reactor systems. Biomass data obtained from both fractions, retained and free suspended biomass, was used for modeling and simulation, together with data for lactose and lactate. The underlying Luedeking-Piret-like model structure was developed based on the results from suspension cultivations with the same strain. The fixed-bed system was described as perfusion culture with cell retention. For this, merely four additional parameters had to be defined to extend the suspension model to fixed-bed cultures. Experimental trends and steady states of both biomass fractions besides substrate and product could be described very well. Thus, this model could be used for process layout during process development.
\end{abstract}

Keywords: Fixed-bed reactor; Immobilization; Lactococcus lactis; LAB; Luedeking-Piret; Modeling; Start-up

Abbreviations and Symbols: D: Dilution rate $\left(\mathrm{h}^{-1}\right)$; DMB: Dry matter of biomass $\left(\mathrm{g} \cdot \mathrm{L}^{-1}\right)$; F: Flow rate $\left(\mathrm{L} \cdot \mathrm{h}^{-1}\right) ; \mathrm{F}_{\text {in }}$ : Inlet flow rat: $(\mathrm{L} \cdot \mathrm{h}$ $\left.{ }^{1}\right) ; \mathrm{F}_{\text {out }}$ : Outlet flow rate $\left(\mathrm{L} \cdot \mathrm{h}^{-1}\right) ; \mathrm{g}$ : Gravitation constant $\left(9.81 \mathrm{~m} \cdot \mathrm{s}^{-2}\right)$; j: Running index; $\mathrm{k}_{\mathrm{lys}}$ : Lysis rate $\left(\mathrm{h}^{-1}\right) ; \mathrm{K}_{\mathrm{s}}$ : Substrate saturation constant $\left(\mathrm{g} \cdot \mathrm{L}^{-1}\right)$; LAB: Lactic acid bacteria; $\mathrm{m}_{\mathrm{r}}$ : Maintenance rate of retained cells $\left(\mathrm{h}^{-1}\right) ; \mathrm{n}$ : Number of data points/values; OD: Optical density (-); $\mathrm{OD}_{600}$ : Optical density determined at $600 \mathrm{~nm}(-)$; P: Product concentration $\left(\mathrm{g} \cdot \mathrm{L}^{-1}\right)$; PLA: Polylactic Acid; $\mathrm{P}_{\text {out }}$ : Product concentration at the outlet $\left(\mathrm{g} \cdot \mathrm{L}^{-1}\right)$; R: Fraction of retained biomass in perfusion fermentation (-); $\mathrm{R}^{2}$ : Correlation coefficient (-); RSS: Residual sum of squares; $\mathrm{S}$ : Substrate concentration $\left(\mathrm{g} \cdot \mathrm{L}^{-1}\right) ; \mathrm{S}_{\text {in }}$ : Substrate concentration at the inlet $\left(\mathrm{g} \cdot \mathrm{L}^{-1}\right) ; \mathrm{S}_{\text {out }}$ : Substrate concentration at the outlet $\left(\mathrm{g} \cdot \mathrm{L}^{-1}\right)$; TCC: Total cell concentration (cells. $\mathrm{mL}^{-1}$ ); TSS Total sum of squares; V: Volume (L); WLS: Weighted least square sum; $\mathrm{w}_{\mathrm{xf}}$ weighting factor for biomass $(=4) ; X_{f}$ : Free suspended biomass concentration $\left(\mathrm{g} \cdot \mathrm{L}^{-1}\right) ; \mathrm{X}_{\mathrm{fout}}$ : Free suspended biomass concentration at the outlet $\left(\mathrm{g} \cdot \mathrm{L}^{-1}\right) ; \mathrm{X}_{\mathrm{r}}$ : Retained biomass concentration $\left(\mathrm{g} \cdot \mathrm{L}^{-1}\right) ; \mathrm{Y}$ : Concentration of either biomass, substrate or product $\left(\mathrm{g} \cdot \mathrm{L}^{-1}\right) ; \hat{\mathrm{Y}}$ : Corresponding simulated value to $\mathrm{Yj}$ $\left(\mathrm{g} \cdot \mathrm{L}^{-1}\right) ; \overline{\mathrm{Y}}_{\mathrm{i}}$ : Arithmetic mean of all Yj either biomass, substrate or product $\left(\mathrm{g} \cdot \mathrm{L}^{-1}\right) ; \mathrm{Y}_{\mathrm{X} / \mathrm{s}}$ : Biomass yield coefficient from substrate $\left(\mathrm{g} \cdot \mathrm{g}^{-1}\right)$; $\alpha$ : Growth associated product formation rate $\left(\mathrm{g} \cdot \mathrm{g}^{-1}\right) ; \beta$ : Non-growth associated product formation rate $\left(\mathrm{h}^{-1}\right) ; \gamma$ : Constant for unspecific substrate loss $\left(\mathrm{L} \cdot \mathrm{g}^{-1} \cdot \mathrm{h}^{-1}\right) ; \mu$ : Specific growth rate $\left(\mathrm{h}^{-1}\right) ; \mu_{\max }$ : Maximum specific growth rate $\left(h^{-1}\right) ; \eta_{\mathrm{P}}$ : Effectiveness factor production $(-)$.

\section{Introduction}

Lactic acid bacteria (LAB) are commonly used in the food industry e.g., for fermenting dairy products or vegetables in order to serve as a preserving agent or to change organoleptic properties of the product [1]. Moreover, some of them evidently act as probiotics [2-5]. High-value compounds produced from LAB can be bacteriocins like nisin, which have an antimicrobial effect and are already added to tooth paste, for instance [6-11]. Another product is microbially produced lactic acid or lactate, which can be provided in an enantiopure manner either as Dor L-lactate [12-14]. Thus, microbial lactate is interesting as a reactant in the PLA (polylactic acid) industry, where the properties of the resulting polymer is strongly dependent on the defined enantiomeric mixture used for polymerization [15].

The Global Industry Analysts Inc. estimated the world production of lactic acid to be 258,000 tons in 2009 and projected it to increase up to 367,000 tons in 2017. Combined with a price of around $1.5 \mathrm{US} \$ / \mathrm{kg}$ for $88 \%$ purity, lactic acid has the potential to become a high-volume chemical intermediate [16]. However, microbial production processes are not yet feasible to compete with chemically produced lactic acid. One possibility to make these processes more profitable is the use of cheap raw materials [17] and to increase productivity. For the latter, fixed-bed processes, where cells are immobilized within macroporous carriers, are a promising alternative to common processes with suspended cells [18-20]. Immobilization of cells on inert porous carriers is an easy way to retain biomass as described in literature for many applications [20-26]. Due to cell retention it is possible to run fixed-bed reactors in a perfusion mode at a steady state with dilution rates higher than the maximum specific growth rate of the used strain.

${ }^{*}$ Corresponding author: Ralf Portner, Institute of Bioprocess and Biosystems Engineering, Hamburg University of Technology, Denickestr. 15, D-21073 Hamburg, Germany, Tel: +4940428782886; Fax: +4940428782909; E-mail: poertner@tuhh.de

Received November 30, 2016; Accepted December 19, 2016; Published December 23, 2016

Citation: Faschian R, Minden S, Portner R (2016) Experimental Investigation and Reaction Kinetics Modeling of Biomass Formation, Substrate Consumption and Product Formation During Start-up of Fixed-Bed Cultures with Immobilized Lactococcus lactis ssp. lactis. J Bioprocess Biotech 6: 294. doi:10.4172/21559821.1000294

Copyright: () 2016 Faschian R, et al. This is an open-access article distributed under the terms of the Creative Commons Attribution License, which permits unrestricted use, distribution, and reproduction in any medium, provided the original author and source are credited. 

Consumption and Product Formation During Start-up of Fixed-Bed Cultures with Immobilized Lactococcus lactis ssp. lactis. J Bioprocess Biotech 6: 294. doi:10.4172/2155-9821.1000294

By this, a very high volume specific productivity with respect to lactate can be reached and maintained for long periods of time. We recently reported on fixed-bed cultures of $L$. lactis, where the volume-specific lactic acid production rate was up to 30 times higher as in batch culture, and continuous cultivation could be maintained for approx. 50 days and a successful scale-up to $1 \mathrm{~L}$-fixed-bed-column with perfusion rates of up to approx. $35 \mathrm{~L}$ per day [27]. Fixed-bed systems can be scaled up to industrial scale by changing the flow pattern from radial to axial perfusion [28].

Nevertheless, the number of industrial fixed-bed processes is quite small. This is due to some extend to the lack of process development tools for fixed-bed processes. A further complicating factor is that fixed-bed processes cannot be designed as easy as processes with homogenously suspended cells. Especially reaction kinetics modeling of biomass formation, substrate consumption and product formation during start-up of fixed bed cultures with immobilized cells has hardly been addressed so far [27]. A description of this initial transient by an appropriate model could be used for prediction of the steady state of fixed-bed processes regarding time and concentrations. Furthermore, influences like changing substrate concentration, dilution rate and initial cell concentration could be simulated. Thereby, the number of experiments could be reduced. The latter one is important during process development to reduce costs because experiments are extraordinarily expensive in case of fixed-bed processes due to long running periods and high dilution rates.

One problem for description and thus modeling of fixed-bed processes using an immobilization matrix is the tedious assessment of retained biomass, which is essential to investigate the time course of biomass formation during start-up and steady state. Sampling is difficult, because cells settle within carriers and only free suspended biomass could be withdrawn from the system. Even if this problem would be addressed somehow, this sample would not be representative for the whole system since fixed-bed reactors are non-homogeneous systems. Attachment of cells within the immobilization matrix can dramatically hinder sampling, especially when solid, inert carriers are used. In homogeneities such as gradients over perfusion height further contribute to this problem. Hence, total retained biomass can only be determined accurately, if the fixed-bed reactor is dismantled and the whole biomass is separated from the carriers and analyzed. As this implies the end of cultivation, a large number of fixed-bed runs would be required to determine the time course of biomass formation within the fixed-bed.

For this purpose, the multi-fixed-bed bioreactor "Multiferm" provides an ideal downscaled system for the development of fixedbed processes with immobilized microorganisms or cells. It consists of twelve single fixed-bed units that can be operated independently [29]. As experiments can be run in parallel, it offers the possibility to determine the progress of biomass formation by analyzing some of the fixed-bed units at different time points. These data were used here to investigate the development of biomass during transient initial phase until a steady state was reached and link these to data on substrate consumption and product formation.

Furthermore, a reaction kinetics model for the fixed-bed culture was set-up based on a model for suspension culture. Modeling approaches from literature showed that the growth behavior of $L$. lactis can be described appropriately by Monod growth kinetics [30]. Concerning homofermentative lactic acid production from LAB in suspended fermentations, the Luedeking-Piret model is the most predominantly used relation in the literature since its first postulation
[31]. This model employs two empirical constants $\alpha$ and $\beta$ that connect the production of lactic acid to growth and biomass, respectively. Most $\mathrm{LAB}$, including L. lactis, show a behavior leading to values of $\alpha$ which are approximately one order of magnitude larger than those for $\beta$ indicating a strong link of product formation to growth rather than maintenance metabolism [32].

Luedeking and Pirets relation was a starting point for many researchers when developing unstructured models for lactic acid fermentations with homofermenters. Jørgensen and Nikolajsen [33] developed a set of differential equations to predict fermentations of $L$. lactis in both, batch and continuous cultivations. Substrate consumption is related to growth via a yield coefficient $Y_{X / S}$ and in addition, a term for microbial maintenance $m$ reflects a specific substrate consumption, which is governed by other cellular processes than growth and proportionally dependent on the current biomass concentration. The Luedeking-Piret expression is then modified by the introduction of a negative constant $\gamma$ expressing reduced product formation in the presence of high sugar levels, which was originally claimed to improve the model in continuous mode.

However, despite its widely distributed application, the LuedekingPiret equation remains challenging to apply for other cultivation modes than batch operation due to the strong dependence of the growth and non-growth associated constants on the culturing condition. Thus, Zacharof and Lovitt [34] suggested the use of yield coefficients for both, substrate and production rates and furthermore, introduced a term for product inhibition into the specific growth rate. This model also considers microbial maintenance. With adequate extensions of the balance equations, this model was successfully tested in batch, continuous and membrane bioreactor systems.

In order to identify a suitable model for different fermentation modes with L. lactis ssp. lactis in this work, both approaches were used as starting point for model set-up. Moreover, since none of the said models is reportedly used to describe immobilized LAB fermentation, further assumptions were required. Since in this work L. lactis was cultivated in a fixed-bed on macroporous carriers, where biomass is retained to some extend within the inner structures of the carriers and between them, suspended and retained biomass had to be considered separately. For this, some authors have employed different interpretations of the dimensionless, internal effectiveness factor $\eta$, which ranges from 0 to 1 and was originally postulated by Thiele to describe reaction rates affected by diffusion limitations within carriers. Up to date, this factor has successfully been used for immobilized ethanol fermentations with yeasts wherein $\eta$ was used in different works to describe the efficiency of the immobilized biocatalyst versus free biocatalyst with respect to biomass formation [35], substrate consumption [36] and ethanol production [35,37].

\section{Materials and Methods}

\section{Bacterial strain}

In this study the type strain Lactococcus lactis ssp. lactis (DSMNo. 20481), in the following denoted as L. lactis, was used. It is a homofermentative strain producing exclusively L-lactate under mesophilic growth conditions $\left(30^{\circ} \mathrm{C}, \mathrm{pH} 7\right)$. As it requires a broad spectrum of nutrients, the complex M17 broth (Difco $\left.{ }^{\mathrm{TM}}, \mathrm{BD}\right)$ was used, which was supplemented with lactose to a final concentration of $5 \mathrm{~g} \cdot \mathrm{L}$ ${ }^{1}$. The medium and the lactose solution were autoclaved separately to avoid the decrease of lactose concentration due to Maillard's reaction.

Since L. lactis is anaerobic and aerotolerant, there was no aeration installed. Thus, also low agitation rates were sufficient to homogenize 
Citation: Faschian R, Minden S, Portner R (2016) Experimental Investigation and Reaction Kinetics Modeling of Biomass Formation, Substrate Consumption and Product Formation During Start-up of Fixed-Bed Cultures with Immobilized Lactococcus lactis ssp. lactis. J Bioprocess Biotech 6: 294. doi:10.4172/2155-9821.1000294

Page 3 of 8

the broth. Mentioned conditions regarding medium, temperature, $\mathrm{pH}$ and aeration were used for all experiments.

\section{Cultivation}

Inoculum preparation: A new preculture was prepared in baffled shaking flasks ( $250 \mathrm{~mL}$ nominal volume) from cryostock for every experiment in the Multiferm. For this purpose, a cryovial containing $10^{\circ}$ cells in $1.5 \mathrm{~mL}$ freezing medium (M17 broth with $10 \%$ (v/v) glycerol) was thawed and transferred to $50 \mathrm{~mL}$ of pre-warmed M17 broth to which lactose was added ( $5 \mathrm{~g} \cdot \mathrm{L}^{-1}$ final concentration). After overnight incubation for approx. $16 \mathrm{~h}$ at $30^{\circ} \mathrm{C}$ and $160 \mathrm{rpm}$ in an orbital shaker, $5 \mathrm{~mL}$ were used to inoculate a second preculture with an inoculation volume of $10 \%(\mathrm{v} / \mathrm{v})$ in shaking flasks. Biomass was determined after $6 \mathrm{~h}$ by counting, and twelve times $10^{9}$ cells were centrifuged $(10 \mathrm{~min}$, $\left.3 \cdot 10^{3} \cdot \mathrm{g}\right)$. The cell pellet was resuspended in fresh lactose supplemented M17 broth to achieve a final concentration of $6.66 \cdot 10^{7}$ cells per $\mathrm{mL}$, which equals $10^{9}$ cells per $15 \mathrm{~mL}$ fixed-bed.

Reactor system used for fixed-bed cultivations: Fermentations of immobilized bacteria were carried out in the multiple fixedbed reactor system Multiferm (medorex e. K, Nörten-Hardenberg, Germany). This system comprises twelve single fixed-bed units with a working volume of $10 \mathrm{ml}$ fixed-bed (carriers) plus $15 \mathrm{~mL}$ of fluid volume each. All units are installed within a conditioning vessel and can be operated independently. For fermentation trials, each unit was filled with $8 \mathrm{~g}$ of borosilicate carriers (diameter: $4 \mathrm{~mm}$, VitraPOR ${ }^{\circ}$, $\mathrm{ROBU}^{\circledR}$ Glasfilter-Geräte $\mathrm{GmbH}$, Hattert, Germany). The $\mathrm{pH}$ was not controlled during continuous cultivation of immobilized cells because preliminary experiments showed that the $\mathrm{pH}$ drops within the units to a level at the outlet, which is not limiting (in average $\mathrm{pH}$ of 6 at $\mathrm{D}=\mu$ max $)$. Temperature was controlled at $30^{\circ} \mathrm{C}$ with a Pt100 sensor and a heating rod, which was located in the water-filled conditioning vessel of the Multiferm. Heating was supported by placing the whole reactor system on a heating plate with magnetic stirrer. Pumps were installed to obtain bottom-to-top perfusion for better degassing of the units. The applied dilution rate was $0.5 \mathrm{~h}^{-1}$ corresponding to the fixed-bed volume of $10 \mathrm{~mL}$, which equals the maximum specific growth rate $\mu_{\max }$ of the used strain in batch cultivation in shaking flasks. All samples except for retained biomass were withdrawn at the outlet (harvest flow) of each fixed-bed unit. This reactor system was established and precisely described in a previous study using a Lactobacillus strain [29].

During continuous fixed-bed cultivation, samples were taken every $48 \mathrm{~h}$. Medium at the outlet was drawn for analysis of lactose and lactate. Moreover, three fixed-bed units were disconnected and dismantled to determine free suspended and immobilized biomass.

Inoculation of the fixed-bed units for continuous cultivation: The autoclaved system, with all twelve units installed and each filled with the carriers, was treated as described in the following:

The water in the conditioning vessel was heated up to $30^{\circ} \mathrm{C}$. A volume of $15 \mathrm{~mL}$ lactose supplemented M17 broth containing $10^{9}$ cells was transferred to every unit. Cells settled within the fixed-bed during $16 \mathrm{~h}$ of incubation. The next morning the exhausted medium was replaced carefully with syringes via the Luer lock connections of each unit. Afterwards perfusion was started at above mentioned dilution rate.

Bioreactor set-up for continuous chemostat cultivation of suspended cells: Fermentations in continuous chemostat mode were realized using the multifermentation system DASGIP ${ }^{\star}$ (eppendorf AG, Germany). The system allows installing of up to four independently controlled reaction vessels with a maximum working volume of $1 \mathrm{~L}$ into a platform where each glass reactor is fixed by a heating collar which was used to maintain a temperature of $30^{\circ} \mathrm{C}$ throughout the fermentations. The Rushton-type stirrer was set at $300 \mathrm{rpm}$ and the $\mathrm{pH}$ regulation was managed by the systems own software DASware ${ }^{\circ}$ control at $7.0 \pm 0.3$ via peristaltic pumps and calibrated $\mathrm{pH}$ electrodes with $5 \mathrm{M} \mathrm{NaOH}$ aq. Medium at room temperature was fed through external, calibrated peristaltic pumps at the bottom of the fermentation broth and the exit flow was installed at the height of the broth surface at a higher flow rate than the inlet flow to ensure a constant volume over time. Before fermentations were started, the $\mathrm{pH}$ regulation system was rinsed with $70 \% \mathrm{EtOH}$ aq according to the systems integrated clean in place (CIP) protocol and three fermentation units were filled with $350 \mathrm{~mL}$ medium without lactose and autoclaved for $15 \mathrm{~min}$ at $121^{\circ} \mathrm{C}$. Subsequently, the fermentation units were placed in the platform and when the medium reached $30^{\circ} \mathrm{C}, 20 \mathrm{~mL} 10 \%(\mathrm{w} / \mathrm{w})$ lactose aq was added to a final concentration of $5 \mathrm{~g} \cdot \mathrm{L}^{-1}$ with the help of Luer lock syringes. For inoculation, a total of $4 \cdot 10^{10}$ cells from a preparatory culture were prepared in $30 \mathrm{~mL}$ fresh medium and inoculated with a syringe.

Each fermenter was connected to an own medium reservoir. Due to the large amount of required medium, reservoirs had to be exchanged twice per fermenter, which was done by reconnecting the respective Luer lock connections under a $70 \% \mathrm{EtOH}$ aq saturated paper towel. Samples of $2 \mathrm{~mL}$ were drawn to collect data about biomass, lactate and lactose. Continuous fermentations were performed three times independently and in parallel and the resulting data is expressed as means \pm SD. The dilution rates were chosen as $0.2,0.4,0.6,0.8$ and 0.9 times the maximum specific growth rate determined from the batch experiments in the Vario 500 system, which was $0.49 \mathrm{~h}^{-1}$.

\section{Analytics}

Biomass: Biomass was analyzed as total cell concentration (TCC) in cells $\cdot \mathrm{mL}^{-1}$ via optical density (OD). TCC was determined using a Neubauer improved counting chamber with a depth of $0.02 \mathrm{~mm}$. To obtain an appropriate cell density, fermentation broth was diluted with $0.9 \%(\mathrm{w} / \mathrm{v}) \mathrm{NaCl}$ solution, if necessary.

OD measurement was carried out in semi-micro cuvettes (Sarstedt, Nümbrecht, Germany) at $600 \mathrm{~nm}$ with a spectrophotometer (V-1200, VWR International, Darmstadt, Germany). Again, samples were diluted with $0.9 \%(\mathrm{w} / \mathrm{v}) \mathrm{NaCl}$ solution to have values in the linear range below 0.6 . In order to distinguish the influence of the broth itself on the measurement, samples were centrifuged $(10 \mathrm{~min}, 3.000 \cdot \mathrm{g})$ and cell-free broth was re-measured. Consequently, OD data in this paper is exclusively the difference of these values.

For determination of immobilized biomass, carriers were rinsed carefully and transferred to $30 \mathrm{~mL}$ of $0.9 \%(\mathrm{w} / \mathrm{v}) \mathrm{NaCl}$ solution. Then, cells were detached via ultrasonic sound (2 min, Bransonic bath 221 , Branson, Dietzenbach, Germany).

The dry content of bacterial mass (DMB, dry matter of biomass) was assessed by drying and weighing of washed fermentation samples according to the following procedure. Samples of $10 \mathrm{~mL}$ fermentation broth were centrifuged for $10 \mathrm{~min}$ at $3 \cdot 10^{3} . \mathrm{g}$ in tared glass vials. After discarding the supernatant, the pellet was resuspended in $2 \mathrm{~mL} 0.9$ $\%(\mathrm{w} / \mathrm{w}) \mathrm{NaCl}$ aq and centrifuged again under the same conditions. Subsequently, the vial was spilled and placed in an oven at $+80^{\circ} \mathrm{C}$ for complete water removal. After at least two days, the biomass was determined by balancing the sample immediately after removal from the oven and DMB was expressed as a concentration in $\mathrm{g} \cdot \mathrm{L}^{-1}$. 
Citation: Faschian R, Minden S, Portner R (2016) Experimental Investigation and Reaction Kinetics Modeling of Biomass Formation, Substrate Consumption and Product Formation During Start-up of Fixed-Bed Cultures with Immobilized Lactococcus lactis ssp. lactis. J Bioprocess Biotech 6: 294. doi:10.4172/2155-9821.1000294

Page 4 of 8

Parallel determination of TCC, OD and DMB during batch cultivations yielded the following correlations:

$$
\begin{array}{ll}
T C C=O D_{600} \cdot 7.36 \cdot 10^{8} & \left(\text { cells. } \mathrm{mL}^{-1}\right) \\
D \mathrm{MB}=O D_{600} \cdot 0.32+0.10 & \left(\text { g. } \mathrm{L}^{-1}\right)
\end{array}
$$

Lactate and lactose concentration: Filter-sterilized samples $(0.22$ $\mu \mathrm{m}$ pore size) were measured with HPLC. Two systems were used, both having a cation exchange column. The first device used $2.5 \mathrm{mM} \mathrm{H}_{2} \mathrm{SO}_{4}$, which flows through the pre-warmed column $\left(40^{\circ} \mathrm{C}, 0.3 \mathrm{~mL} \cdot \mathrm{min}^{-1}\right)$. A refractive index detector analyzed all components. The second device used $5 \mathrm{mM}$ sulfuric acid as eluent at a flow rate and has 0.6 $\mathrm{mL} \cdot \mathrm{min}^{-1}$. Lactose was again measured by a refractive index detector and additionally, a UV-detector was used to assess lactate (Kontron Instruments, Kontron HPLC 332 UV detector, RID-6A Shimadzu infrared detector, BioRad Aminex HPX-87H column at $50^{\circ} \mathrm{C}$ ).

\section{Methods used with respect to modeling}

Parameter estimation: Model-specific parameters were determined by fitting of the model curve to the experimental data. This was realized by minimizing a weighted least sum of squares function by using the MATLAB subroutine $f m i n$ search. Beforehand, differential equations of the model were solved by the ode 45 algorithm with variable step width from MATLAB using initial guesses. Since biomass concentrations are four times lower in average, DMB values were weighted by a factor of 4 to have the same influence as lactose and lactate levels on the parameter estimation, which was realized by minimizing a weighted least sum of squares function comparing simulated to experimental data according to the following equation:

$$
\text { WLS }=\sum_{\mathrm{j}=1}^{\mathrm{n}}\left(\hat{\mathrm{X}}_{f, \mathrm{j}}-\mathrm{X}_{f, \mathrm{j}}\right)^{2} \cdot \mathrm{W}_{x f}+\sum_{\mathrm{j}=1}^{\mathrm{n}}\left(\hat{\mathrm{S}}_{\mathrm{j}}-\mathrm{S}_{\mathrm{j}}\right)^{2}+\sum_{\mathrm{j}=1}^{\mathrm{n}}\left(\hat{\mathrm{P}}_{\mathrm{j}}-\mathrm{P}_{\mathrm{j}}\right)^{2}
$$

WLS=weighted least square

$\mathrm{n}=$ number of values

$j=$ running index

$X_{f, j}, S_{j}, P_{j}=$ concentration of either free suspended biomass, substrate or product

$$
\hat{\mathrm{X}}_{f, \mathrm{j}}, \hat{\mathrm{S}}_{\mathrm{j}}, \hat{\mathrm{P}}_{\mathrm{j}}=\text { corresponding simulated value }
$$

$\mathrm{w}_{\mathrm{xf}}=$ weighting factor for free suspended biomass $(=4)$

Note that for cultivations with immobilized biomass the weighting factor for free suspended biomass fraction equals 1 in order to hit the behavior during fixed-bed cultivation. Additionally, another term for retained biomass containing $X_{r, j}$ was included.

Evaluation of simulations: The simulation was evaluated by calculating the coefficient of determination $R^{2}$ as

$$
\mathrm{R}^{2}=1-(\mathrm{RSS} / \mathrm{TSS})
$$

where the residual sum of squares (RSS) was normalized to the total sum of squares (TSS) according to the following two equations:

$$
\mathrm{RSS}=\sum_{\mathrm{j}=1}^{\mathrm{n}}\left(\hat{\mathrm{Y}}_{\mathrm{j}}-\mathrm{Y}_{\mathrm{j}}\right)^{2}
$$

$\mathrm{n}$ number of values

$\mathrm{J} \quad$ running index

$\mathrm{Y}_{j} \quad$ concentration of either biomass, substrate or product
$\hat{\mathrm{Y}}_{j} \quad$ corresponding simulated value

$\overline{\mathbf{y}}_{j} \quad$ arithmetic mean of all measured values of either biomass, substrate or product

\section{Results and Discussion}

Time course of biomass, substrate and product during fixedbed cultivation

The aim of these studies was to investigate how bacteria proliferate during transient initial phase of fixed-bed cultivation until a steady state point of operation is reached, where all concentrations of substrate, product and biomass in the outlet are constant. The chronology of pictures in Figure 1 shows how biomass changes over the cultivation period of eight days (192 h). In the beginning, there is only few biomass within the system. At the end, an enormous formation of biomass is visible. Additionally, it can be seen that biomass grew from bottom to top. The underlying mechanism was not investigated further but compared with recent studies it seems to happen due to gravitational effects instead of any limitation at this fixed-bed size and dilution rate. For scale-up, limitation is addressed by changing the flow from axial to radial perfusion.

L. lactis did not form a stable biofilm under the applied conditions and cells are rather retained by deep-filtration effects. Furthermore, cells sedimented on the bottom of the fixed-bed unit where the medium enters the reactor from the inner tube in bottom-to-top perfusion. Therefore, the biomass was divided into two fractions, one being free suspended cells and the other summarizing sedimented cells and cells within the carriers. The latter fraction is referred as retained biomass. Retained biomass is related to the whole liquid volume of $15 \mathrm{~mL}$ within a reaction unit.

The time course of free suspended and retained cells as well as of substrate (lactose) and product (lactate) concentrations are plotted in Figure 2. The standard deviation is very small, underlining the high reproducibility of the multiple fixed-bed runs. The suspended DMB remained stable at concentrations between $0.16 \mathrm{~g} \cdot \mathrm{L}^{-1}$ and $0.47 \mathrm{~g} \cdot \mathrm{L}^{-1}$. In contrast, retained biomass increased linearly from initially $0.3 \mathrm{~g} \cdot \mathrm{L}^{-1}$ to $11.20 \mathrm{~g} \cdot \mathrm{L}^{-1}$ on day six to stay constant until day eight.

The lactose concentration decreased from the initial value of $5 \mathrm{~g} \cdot \mathrm{L}$ ${ }^{1}$ to nearly zero (below detection limit) for all subsequent sampling points. Simultaneously, the lactate concentration increased up to a maximum of $16.28 \mathrm{~g} \cdot \mathrm{L}^{-1}$ on the second day and remained constant for days six and eight at $12.55 \mathrm{~g} \cdot \mathrm{L}^{-1}$. It is obvious that the strain was able to metabolize complex components of the M17 broth since the lactate values were three to five times elevated versus the initial lactose value. The volume specific lactate productivities resulted in values of $4.69 \mathrm{~g} \cdot \mathrm{L}$ ${ }^{1} \cdot \mathrm{h}^{-1}$ (day six) and $4.72 \mathrm{~g} \cdot \mathrm{L}^{-1} \cdot \mathrm{h}^{-1}$ (day eight). These values are in very good agreement with data from experiments in larger fixed-beds (fixed-bed volume $100 \mathrm{~mL}: 4.7 \mathrm{~g} \cdot \mathrm{L}^{-1} \cdot \mathrm{h}^{-1}$, fixed-bed volume $1 \mathrm{~L}: 4.8 \mathrm{~g} \cdot \mathrm{L}^{-1} \cdot \mathrm{h}^{-1}$, data

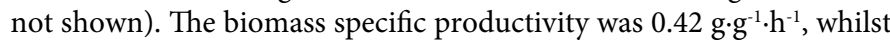
the yield was calculated to be $1.89 \mathrm{~g} \cdot \mathrm{g}^{-1}$. This value is greater than 1 , again for the above mentioned reason of complex medium component utilization. This data set was used for modeling as described in the next section.

\section{Model development for biomass, substrate and product}

To consider both biomass fractions (free and retained), the fixedbed system was described as a perfusion system consisting of a cell suspension coupled with a cell retention unit, where not all free cells 
Citation: Faschian R, Minden S, Portner R (2016) Experimental Investigation and Reaction Kinetics Modeling of Biomass Formation, Substrate Consumption and Product Formation During Start-up of Fixed-Bed Cultures with Immobilized Lactococcus lactis ssp. lactis. J Bioprocess Biotech 6: 294. doi:10.4172/2155-9821.1000294

Page 5 of 8

Day 0

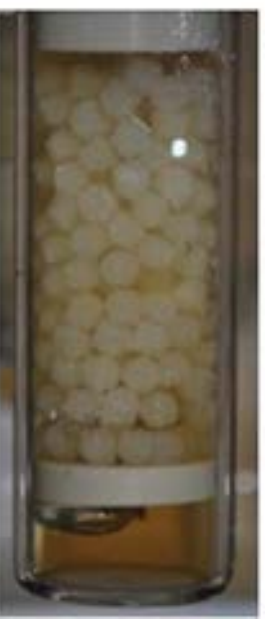

Day 4

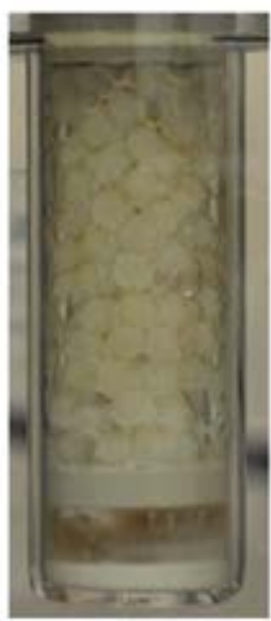

Figure 1: Photographic chronology of biomass during continuous fixed-bed fermentations. Cultivation for $192 \mathrm{~h}$ at $30^{\circ} \mathrm{C}$ with M17 broth (final lactose concentration at the inlet: $\left.5 \mathrm{~g} \cdot \mathrm{L}^{-1}\right)$. Dilution rate $D$ was equal to the maximum specific growth rate max during batch cultivations of suspended cells $\left(0.5 \mathrm{~h}^{-1}\right)$. Pictures were taken on day 0,4 and 8 .

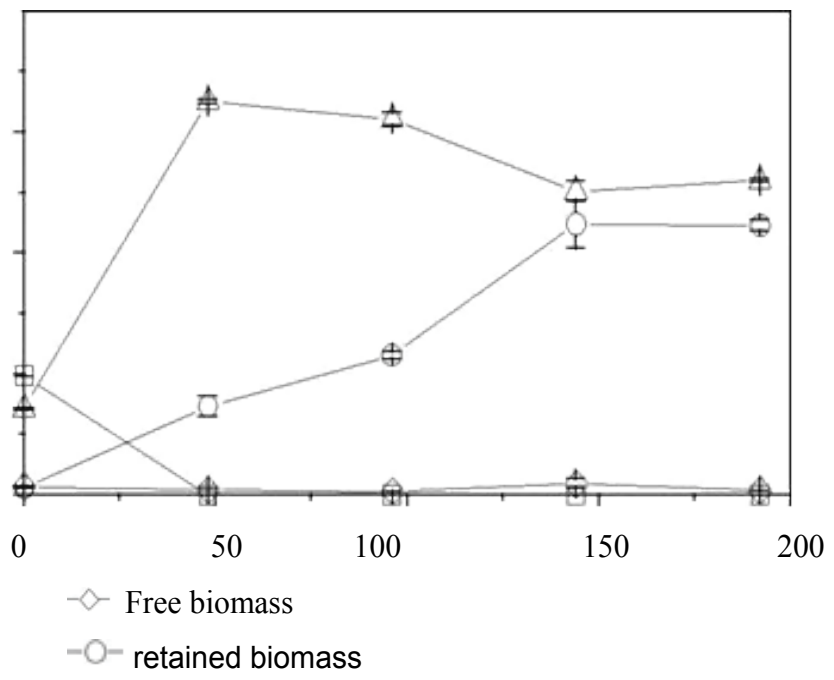

Figure 2: Time courses of free biomass, retained biomass, lactose and lactate during continuous fixed-bed cultivations of $L$. lactis ${ }_{\mu}$ in the Multiferm. Conditions: M17 broth with $5 \mathrm{~g} \cdot \mathrm{L}^{-1}$ lactose, constant dilution rate ${ }_{n}$ at $D=\max =0.5 \mathrm{~h}^{-1}, 30^{\circ} \mathrm{C}$ and an initial $\mathrm{pH}$ of 7 . Data points are means \pm standard deviation $(=2-4)$.

leave the system but stay within the system (fixed-bed reactor) and contribute to the fraction of retained cells (Figure 3).

Therefore, a perfusion constant $R$ had to be introduced to the differential equations for biomass (see below). The retained biomass reaches a steady state after constant increase. Hence, this fraction is not regarded as growing rather than being produced via retaining of free cells. Furthermore, the retained fraction is allowed to "lyse" in order to reach and stay at a maximum value, which was realized by introducing a lysis constant $k_{l y s}$. Growth of free suspended biomass was described by Monod growth kinetics [30].

$$
\mu=\mu_{\max } \cdot \frac{\mathrm{S}}{\mathrm{S}+\mathrm{K}_{\mathrm{S}}}
$$

\section{$\mu=$ specific growth rate}

$\mu_{\max }=$ maximum specific growth rate

$S=$ running index

\section{$\mathrm{K}_{\mathrm{S}}=$ Monod-constant}

Own studies revealed that at substrate concentrations below $5 \mathrm{~g} \cdot \mathrm{L}^{-1}$ lactose no term for product inhibition has to be included to improve the model notably. Substrate consumption of free suspended biomass was described by using a yield coefficient $Y_{X / S}$ because it turned out that maintenance is negligible for suspended cells. Product formation can be modeled with a Luedeking-Piret equation [31] containing expressions for growth correlated formation ( $\alpha$-term), non-growth correlated formation by plain biomass ( $\beta$-term) and unspecific substrate consumption ( $\gamma$-term) [33] that does not contribute to the product.

Substrate consumption by retained cells was considered by a maintenance coefficient $m_{r}$ in the differential equation for substrate. An additional $\beta$-term for retained biomass introduced in the differential equation for product, which is adjusted with an effectiveness factor $\eta_{P}$ [35-37] that stands for the relative difference between non-growth associated production of lactate from free and retained cells.

Finally, the model to describe fixed-bed cultivations consists of the following set of differential equations:

$$
\begin{aligned}
& \frac{d_{X_{f}}}{d t}=X_{f} \cdot \mu-D \cdot(1-R) \cdot X_{f} \\
& \frac{d X_{r}}{d t}=D \cdot R \cdot X_{f}-k_{l y s} \cdot X_{r} \\
& \frac{d S}{d t}=-\frac{X_{f} \cdot \mu}{Y_{X / s}}-m_{r} \cdot X_{r}+D \cdot\left(S_{i n}-S\right) \\
& \frac{d P}{d t}=\alpha \cdot X_{f} \cdot \mu+\beta \cdot X_{f}-\gamma \cdot X_{f} \cdot S+\beta \cdot X_{r} \cdot \eta_{P}-D \cdot P
\end{aligned}
$$

$\mathrm{X}_{\mathrm{f}} \quad$ free suspended biomass

$\mathrm{X}_{\mathrm{r}} \quad$ retained biomass

$\mathrm{P}$ product concentration

D dilution rate

Note that compared to the reaction kinetic model of a chemostat cultivation of suspended L. lactis cells, there is only one additional equation for retained biomass and overall, only four new parameters $\left(R, k_{l y s}, m_{r}\right.$ and $\left.\eta_{p}\right)$ were introduced.

Those model parameters in eq. 7-10 related to growth, substrate consumption and product formation of free suspended biomass $\left(\mu_{\max }\right.$ $\left.K_{s}, Y_{x / s}, \alpha, \beta, \gamma\right)$ were estimated from chemostat cultures. The results of the parameter estimation are listed in Table 1. Model selection and parameter estimation are discussed in detail in Ref. [38].

These parameters were used as a starting point for estimation of the parameters specific for the retained biomass $\left(R, k_{\text {lys }}, m_{r}\right.$ and $\left.\eta_{p}\right)$. Table 2 summarizes the results of the estimated four fixed-bed specific parameters.

A perfusion constant $\mathrm{R}$ of 0.37 reveals that only $63 \%$ of free suspended cells leave the system. The fitted lysis rate $\mathrm{k}_{\mathrm{lys}}$ means that 0.3 $\%$ of retained cells lyse per hour. The calculated effectiveness factor $\eta_{\mathrm{P}}$ is 
Citation: Faschian R, Minden S, Portner R (2016) Experimental Investigation and Reaction Kinetics Modeling of Biomass Formation, Substrate Consumption and Product Formation During Start-up of Fixed-Bed Cultures with Immobilized Lactococcus lactis ssp. lactis. J Bioprocess Biotech 6: 294. doi:10.4172/2155-9821.1000294

Page 6 of 8

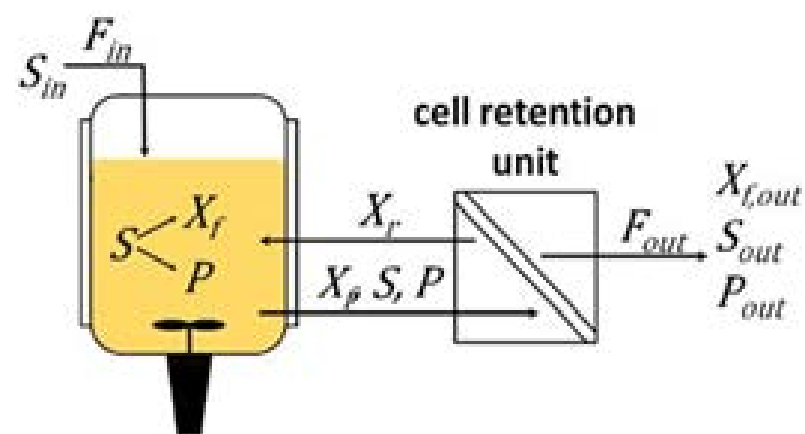

Figure 3: Scheme for modeling of the fixed-bed system with free and retained biomass.

\begin{tabular}{|c|c|c|c|c|c|}
\hline $\boldsymbol{\mu}_{\max }$ & $\mathbf{K}_{\mathbf{s}}$ & $\mathbf{Y}_{\mathrm{x} / \mathbf{s}}$ & $\boldsymbol{\alpha}$ & $\boldsymbol{\beta}$ & $\mathbf{Y}$ \\
\hline$\left(\mathrm{h}^{-1}\right)$ & $\left(\mathrm{g} \cdot \mathrm{L}^{-1}\right)$ & $\left(\mathrm{g} \cdot \mathrm{g}^{-1}\right)$ & $\left(\mathrm{g} \cdot \mathrm{g}^{-1}\right)$ & $\left(\mathrm{h}^{-1}\right)$ & $\left(\mathrm{L} \cdot \mathrm{g}^{-1} \cdot \mathrm{h}^{-1}\right)$ \\
\hline 0.48 & 0.24 & 0.18 & 10.22 & 0.12 & 0.53 \\
\hline
\end{tabular}

Table 1: Parameter values from curve fitting of batch fermentation data of suspended L. lactis (M17 broth, $30^{\circ} \mathrm{C}, 5 \mathrm{~g} \cdot \mathrm{L}^{-1}$ lactose). Model and parameters were evaluated in continuous fermentation.

\begin{tabular}{|c|c|c|c|}
\hline $\mathbf{R}$ & $\mathbf{k}_{\text {lys }}$ & $\mathbf{m}_{\mathbf{r}}$ & $\mathbf{\eta}_{\mathbf{p}}$ \\
\hline$(-)$ & $\left(\mathrm{h}^{-1}\right)$ & $\left(\mathrm{h}^{-1}\right)$ & $(-)$ \\
\hline 0.37 & $2.92 \times 10^{-3}$ & 0.21 & 6.16 \\
\hline
\end{tabular}

Table 2: Parameter values from curve fitting of fixed-bed fermentation data of $L$. lactis (M17 broth, $30^{\circ} \mathrm{C}, 5 \mathrm{~g} \cdot \mathrm{L}^{-1}$ lactose).

equal to a six-fold increase of non-growth correlated lactate production from retained cells versus free cells.

\section{Simulation versus experimental data}

Figure 4 shows simulations of time courses for free and retained biomass as well as levels of lactose and lactate versus time compared to the corresponding experimental data set. In general, simulations of free and suspended biomass (both expressed as DMB) show a good description of the time courses for both fractions. The simulation of free biomass reaches a maximum in the beginning after $10 \mathrm{~h}$ of fermentation time of $1.08 \mathrm{~g} \cdot \mathrm{L}^{-1}$. Afterwards, the steady state value of $0.15 \mathrm{~g} \cdot \mathrm{L}^{-1}$ was reached after $120 \mathrm{~h}$. The simulation of retained biomass reaches the steady state earlier than the experimental data indicates and only to $76 \%$ of the experimental value. The simulated time course of lactose concentration predicts a decrease within the first $10 \mathrm{~h}$ of fermentation from initially $5 \mathrm{~g} \cdot \mathrm{L}^{-1}$ to $0.36 \mathrm{~g} \cdot \mathrm{L}^{-1}$ what represents very well what was observed in the experiment, where lactose level also dropped under the detection limit of $0.5 \mathrm{~g} \cdot \mathrm{L}^{-1}$. The simulated lactate trend shows a mild decrease in the first $1.5 \mathrm{~h}$ of fermentation due to dilution effects. Then it increases logarithmically up to $14.73 \mathrm{~g} \cdot \mathrm{L}^{-1}$ at $120 \mathrm{~h}$ process time. This value is very close to the steady state of experimental data.

Tables 3-6 summarizes the coefficients of determination for all simulated trends. The time courses of retained cells and for the product concentration can be described adequately by the simulation as indicated by values of 0.724 and 0.796 , respectively. An excellent description by simulation was received with the underlying model for the substrate trend. The calculated $R^{2}$ value for simulated free suspended biomass led to a negative value. This is due the low concentrations of free suspended biomass and thus, the relative deviations between simulated and experimental data are large.

\begin{tabular}{|c|c|c|c|c|}
\hline & $\mathbf{X}_{\mathbf{f}}$ & $\mathbf{X}_{\mathbf{r}}$ & $\mathbf{S}$ & $\mathbf{P}$ \\
\hline & $\left(\mathrm{g} \cdot \mathrm{L}^{-1}\right)$ & $\left(\mathrm{g} \cdot \mathrm{L}^{-1}\right)$ & $\left(\mathrm{g} \cdot \mathrm{L}^{-1}\right)$ & $\left(\mathrm{g} \cdot \mathrm{L}^{-1}\right)$ \\
\hline $\mathbf{R}^{2}$ & -2.076 & 0.724 & 0.979 & 0.796 \\
\hline
\end{tabular}

Table 3: Coefficients of determination $R^{2}$ for the simulations of free biomass retained biomass, lactose and lactate as shown in Figure 4.

\begin{tabular}{|c|c|c|c|c|c|}
\hline $\boldsymbol{\mu}_{\max }$ & $\mathbf{K}_{\mathbf{s}}$ & $\mathbf{Y}_{\mathrm{xls}}$ & $\boldsymbol{\alpha}$ & $\boldsymbol{\beta}$ & $\mathbf{Y}$ \\
\hline$\left(\mathrm{h}^{-1}\right)$ & $\left(\mathrm{g} \cdot \mathrm{L}^{-1}\right)$ & $\left(\mathrm{g} \cdot \mathrm{g}^{-1}\right)$ & $\left(\mathrm{g} \cdot \mathrm{g}^{-1}\right)$ & $\left(\mathrm{h}^{-1}\right)$ & $\left(\mathrm{L} \cdot \mathrm{g}^{-1} \cdot \mathrm{h}^{-1}\right)$ \\
\hline 0.48 & 0.24 & 0.18 & 10.22 & 0.12 & 0.53 \\
\hline
\end{tabular}

Table 4: Parameter values from curve fitting of batch fermentation data of suspended $\mathrm{L}$. lactis (M17 broth, $30^{\circ} \mathrm{C}, 5 \mathrm{~g} \cdot \mathrm{L}^{-1}$ lactose). Model and parameters were evaluated in continuous fermentation.

\begin{tabular}{|c|c|c|c|}
\hline $\mathbf{R}$ & $\mathbf{k}_{\text {lys }}$ & $\mathbf{m}_{\mathbf{r}}$ & $\mathbf{\eta}_{\mathbf{p}}$ \\
\hline$(-)$ & $\left(\mathrm{h}^{-1}\right)$ & $\left(\mathrm{h}^{-1}\right)$ & $(-)$ \\
\hline 0.37 & $2.92 \times 10^{-3}$ & 0.21 & 6.16 \\
\hline
\end{tabular}

Table 5: Parameter values from curve fitting of fixed-bed fermentation data of $L$. lactis (M17 broth, $30^{\circ} \mathrm{C}, 5 \mathrm{~g} \cdot \mathrm{L}^{-1}$ lactose)

\begin{tabular}{|c|c|c|c|c|}
\hline & $\mathbf{X}_{\mathbf{f}}$ & $\mathbf{X}_{\mathrm{r}}$ & $\mathbf{S}$ & $\mathbf{P}$ \\
\hline & $\left(\mathrm{g} \cdot \mathrm{L}^{-1}\right)$ & $\left(\mathrm{g} \cdot \mathrm{L}^{-1}\right)$ & $\left(\mathrm{g} \cdot \mathrm{L}^{-1}\right)$ & $\left(\mathrm{g} \cdot \mathrm{L}^{-1}\right)$ \\
\hline $\boldsymbol{R}^{\mathbf{2}}$ & -2.076 & 0.724 & 0.979 & 0.796 \\
\hline
\end{tabular}

Table 6: Coefficients of determination $\mathrm{R}^{2}$ for the simulations of free biomass, retained biomass, lactose and lactate as shown in Figure 4.

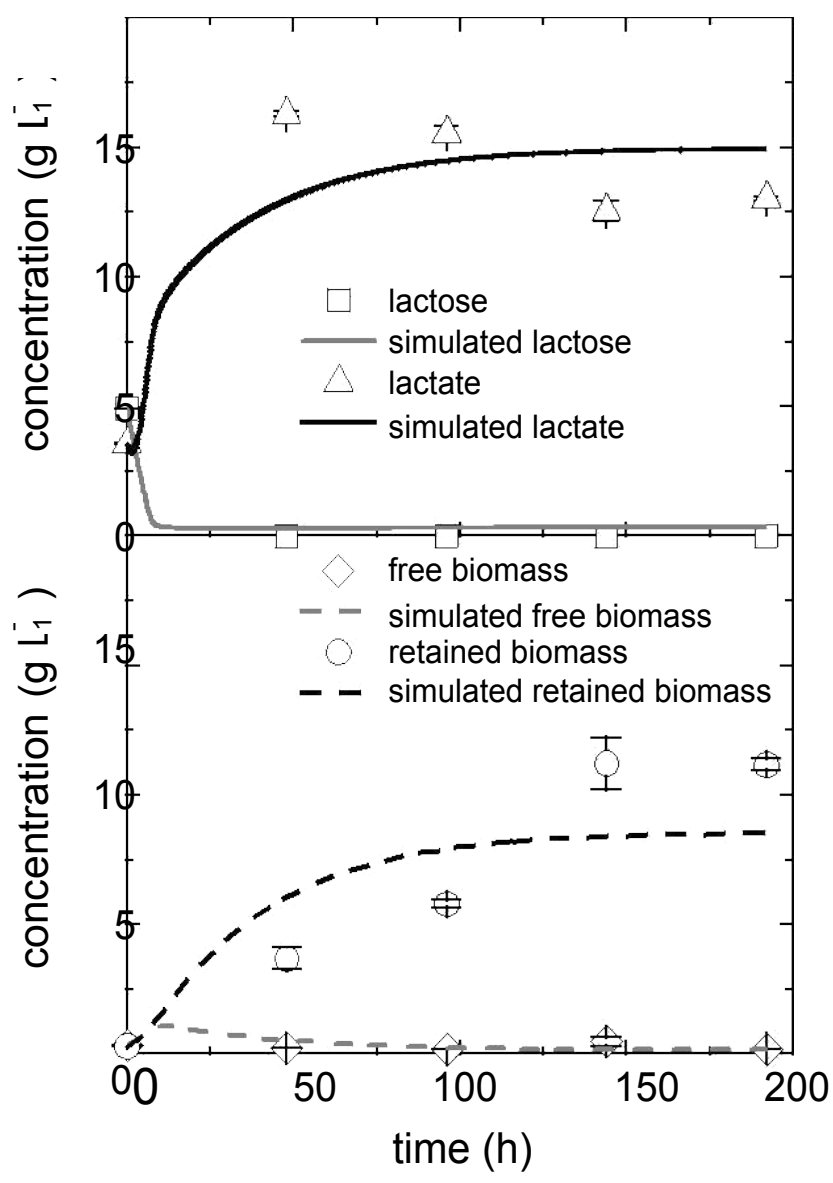

Figure 4: Simulation of free and retained biomass, lactose and lactate vs. experimental data. 
Citation: Faschian R, Minden S, Portner R (2016) Experimental Investigation and Reaction Kinetics Modeling of Biomass Formation, Substrate Consumption and Product Formation During Start-up of Fixed-Bed Cultures with Immobilized Lactococcus lactis ssp. lactis. J Bioprocess Biotech 6: 294. doi:10.4172/2155-9821.1000294

\section{Conclusion}

In this study the down-scaled multiple fixed-bed fermenter system Multiferm was used to investigate biomass formation during cultivations of a L. lactis ssp. lactis strain. Especially the initial transient state was of interest in order to use the data for modeling and simulation. Retained and free suspended biomass was determined successfully by dismantling three units every $48 \mathrm{~h}$ beginning on day zero up to day eight resulting in five sample points and 15 values in total. Since the Multiferm has a compact design with twelve single fixed-bed units in one vessel, the system had to be prepared only twice to get all necessary values. Therefore, the usage of this reactor system accelerated the experimental effort drastically.

The straightforward modeling approach based on suspension cultivations in chemostat mode resulted in a model, which could be extended to adequately describe the fixed-bed process by introducing only four new parameters. The main idea of modeling the free suspended biomass as a perfusion-like system, where only a part leaves the reactor and the other contributes to non-growing but accumulating retained biomass, led to an adequate description of the fixed-bed process. Further studies will focus on scale-up of the fixed-bed system and optimization of process parameters, e.g., perfusion rates.

\section{Conflict of Interest}

The authors confirm that they do not have any conflicts of interest.

\section{Funding and Acknowledgements}

The financial support from Federal Ministry of Education and Research (BMBF) under grant No. 0.31A124A ("ProTool 2") is gratefully acknowledged just as the work of the project partners (Ingenieurbüro Schoop, medorex e.K. and Prof. Dr. Ing Hass from Hochschule Furtwangen). The project is part of the BIOKATALYSE2021 cluster.

\section{References}

1. Mayo B, Aleksandrzak-Piekarczyk T, Fernndez M, Kowalczyk M, Martin PA et al. (2010) Updates in the Metabolism of Lactic Acid Bacteria. In: Mozzi F, Raya RR, Vignolo GM (eds.). Biotechnology of Lactic Acid Bacteria: Novel Applications, Wiley-Blackwell, Oxford, UK, pp: 3-33.

2. Doleyres Y, Fliss I, Lacroix C (2004) Continuous Production of Mixed Lactic Starters Containing Probiotics Using Immobilized Cell Technology. Biotechnol Progr 20: 145-150.

3. Lacroix C, Yildirim S (2007) Fermentation technologies for the production of probiotics with high viability and functionality. Curr Opin Chem Biotechnol 18: 176-183.

4. Leroy $F$, Vuyst $L$ de (2004) Lactic acid bacteria as functional starter cultures for the food fermentation industry. Trends Food Sci Tech 15: 67-78.

5. Lukic J, Strahinic I, Jovcic B, Filipic B, Topisirović L, et al. (2012) Different Roles for Lactococcal Aggregation Factor and Mucin Binding Protein in Adhesion to Gastrointestinal Mucosa. Appl Environ Microbiol 78: 7993-8000.

6. Taniguchi M, Hoshino K, Urasaki H, Fujii M (1994) Continuous production of an antibiotic polypeptide (nisin) by Lactococcus lactis using a bioreactor coupled to a microfiltration module. J Ferment Bioengineer 77: 704-708.

7. Bertrand N, Fliss I, Lacroix C (2001) High nisin-Z production during repeatedcycle batch cultures in supplemented whey permeate using immobilized Lactococcus lactis UL719. Int Dairy J 11: 953-960.

8. Desjardins P, Meghrous J, Lacroix C (2001) Effect of aeration and dilution rate on nisin $\mathrm{Z}$ production during continuous fermentation with free and immobilized Lactococcus lactis UL719 in supplemented whey permeate. International Dairy Journal 11: 943-951.

9. Pongtharangkul T, Demirci A (2006) Effects of $\mathrm{pH}$ profiles on nisin production in biofilm reactor. Appl Microbiol Biotechnol 71: 804-811.

10. Scannell A, Hill C, Ross R, Marx S, Hartmeier W, et al. (2000) Continuous production of lacticin 3147 and nisin using cells immobilized in calcium alginate. J Appl Microbiol 89: 573-579.
11. Wan J, Hickey MW, Coventry MJ (1995) Continuous production of bacteriocins brevicin, nisin and pediocin, using calcium alginate-immobilized bacteria. $J$ Appl Bacteriol 79: 671-676.

12. Pot B, Felis GE, Bruyne KD, Tsakalidou E (2014) The genus Lactobacillus. In: Holzapfel WH, Wood BJ, (eds.). Lactic Acid Bacteria: Biodiversity and Taxonomy. John Wiley \& Sons Ltd, Chichester, UK, pp: 249-353.

13. Kim W (2014) The genus Lactococcus. In: Holzapfel WH, Wood BJ (eds.) Lactic Acid Bacteria: Biodiversity and Taxonomy. John Wiley \& Sons Ltd, Chichester UK, pp: 429-443.

14. Kandler O (1983) Carbohydrate metabolism in lactic acid bacteria. Antonie van Leeuwenhoek 49: 209-224

15. Jin Z, Tian Y, Wang J (2010) Chemistry and Thermodynamic Properties of Lactic Acid and Lactide and Solvent Miscibility, John Wiley \& Sons Inc.

16. Subramanian MR, Talluri S, Christopher LP (2015) Production of lactic acid using a new homofermentative Enterococcus faecalis isolate. Microbial biotechnology 8: 221-229.

17. Lamboley L, Lacroix C, Artignan J, Champagne C, Vuillemard JC, et al. (1999) Long-Term Mechanical and Biological Stability of an Immobilized Cell Reactor for Continuous Mixed-Strain Mesophilic Lactic Starter Production in Whey Permeate. Biotechnol Prog 15: 646-654.

18. Dagher SF, Ragout AL, Siñeriz F, Bruno-Bárcena JM (2010) Cell immobilization for production of lactic acid biofilms do it naturally. Adv Appl Microbiol 71: 113148.

19. Lacroix C, Grattepanche F, Doleyres Y, Bergmaier D (2005) Immobilised Cell Technologies for the Dairy Industry. In: Nedovic V, Willaert R (eds.) Applications of Cell Immobilisation Biotechnology, Springer Netherlands, pp: 295-319.

20. Pörtner R, Seemuk M, Schlothauer RC, Elsser D (2004) Anaerobe Kultivierung von Lactococcus lactis im Festbettreaktor. Chemie Ingenieur Technik 76: 15991602.

21. Goncalves L, Barreto M, Xavier A, Carrondo M, Klein J, et al. (1992) Inert supports for lactic acid fermentation - a technological assessment. Appl Microbiol Biotechnol 38: 305-311.

22. Chantawongvuti R, Veerajetbodithat J, Jaturapiree P, Muangnapoh C (2010) Immobilization of Lactobacillus salivarius ATCC 11741 on loofa sponge coated with chitosan for lactic acid fermentation. J. Microbiol. Biotechnol 20: 110-116.

23. Bruno-Bárcena JM, Ragout AL, Córdoba PR, Sineriz F (1999) Continuous production of $L(+)$-lactic acid by Lactobacillus casei in two-stage systems. Appl Microbiol Biotechnol 51: 316-324.

24. Tango MSA, Ghaly AE, (2002) A continuous lactic acid production system using an immobilized packed bed of Lactobacillus helveticus. Appl Microbiol Biotechnol 58: 712-720.

25. Roble ND, Ogbonna JC, Tanaka H (2003) L-Lactic acid production from raw cassava starch in a circulating loop bioreactor with cells immobilized in loofa (Luffa cylindrica). Biotechnol Lett 25: 1093-1098.

26. Bergmaier D, Champagne C, Lacroix C (2003) Exopolysaccharide production during batch cultures with free and immobilized Lactobacillus rhamnosus RW9595M. J Appl Microbiol 95: 1049-1057.

27. Pörtner R, Faschian $R$, Goelling $D$ (2016) Fermentation of Lactic Acid Bacteria: State of the Art and New Perspectives. In: Liese A, Hilterhaus L, Kettling $U$ Antranikian G. (eds.) Applied Biocatalysis: From Fundamental Science to Industrial Applications, Wiley- $\mathrm{VCH}$, (in print).

28. Fassnacht D, Reimann I, Pörtner R, Märkl H (2001) Scale up von Festbettreaktoren zur Kultivierung tierischer Zellen. Chemie Ingenieur Technik 73: 1075-1079.

29. Faschian R, De S, Pörtner R (2016) Multi-Fixed-Bed Bioreactor System Applied for Bioprocess Development of Immobilized Lactic Acid Bacteria. The Open Biotechnology Journal 10: 1-9.

30. Monod J (1949) The Growth of Bacterial Cultures. Annu Rev Micobiol 3: 371 394.

31. Luedeking R, Piret EL (1959) A kinetic study of the lactic acid fermentation Batch process at controlled pH. Biotechnol Bioeng 1: 393-412.

32. Boonmee M, Leksawasdi N, Bridge W, Rogers PL (2003) Batch and continuous culture of Lactococcus lactis NZ133: Experimental data and mode development. Biochem Eng J 14: 127-135. 
Citation: Faschian R, Minden S, Portner R (2016) Experimental Investigation and Reaction Kinetics Modeling of Biomass Formation, Substrate Consumption and Product Formation During Start-up of Fixed-Bed Cultures with Immobilized Lactococcus lactis ssp. lactis. J Bioprocess Biotech 6: 294. doi:10.4172/2155-9821.1000294

Page 8 of 8

33. Jørgensen M, Nikolajsen K (1987) Mathematic model for lactic acid formation with Streptococcus cremoris from glucose. Appl Microbiol Biotechnol 25: 313316.

34. Zacharof MP, Lovitt RW (2013) Modelling and simulation of cell growth dynamics, substrate consumption, and lactic acid production kinetics of Lactococcus lactis. Biotechnol Bioproc Eng 18: 52-64.

35. Kostov G, Popova S, Gochev V, Koprinkova-Hristova P, Angelov M, et al. (2014) Modeling of Batch Alcohol Fermentation with Free and Immobilized Yeasts Saccharomyces Cerevisiae 46 EVD. Biotechnology \& Biotechnological

\section{Equipment 26: 3021-3030}

36. Prasad B, Mishra I (1995) On the kinetics and effectiveness of immobilized whole-cell batch cultures. Bioresource Technology 53: 269-275.

37. Slininger PJ, Bothast RJ, Black LT, McGhee JE (1982) Continuous conversion of $D$-xylose to ethanol by immobilized pachysolen tannophilus. Biotechno Bioeng 24: 2241-2251.

38. Minden S, Faschian R, Pörtner R (2016) Evaluation of Kinetics Growth Models and Parameter Estimation in Batch and Chemostat Mode of Suspended Lactococcus lactis ssp. lactis. 